\title{
Wittgenstein's Early Philosophy, [edited] by José L. Zalabardo. Oxford: Oxford University Press, 2012, viii + 274 pp. ISBN 978-0-19-969152-4 £31.50
}

[PENULTIMATE DRAFT]

This welcome addition to the literature on Wittgenstein's early work comprises nine new essays and a helpful introduction by the editor. Together with other recent publications, the collection contributes to a shift of focus in early Wittgenstein scholarship away from schismatic disputes about how to conceive of the Tractatus as a whole in light of its notorious, climactic selfdisavowal. Though these issues are touched upon in several chapters, the focus in this volume is on Wittgenstein's early views on three broad topics: judgement, objects, and philosophical method. In addition to the Tractatus, considerable attention is given to Wittgenstein's preTractarian writings and to his engagement with the views of Frege and Russell.

In the first chapter, 'Russell, Wittgenstein and Synthesis in Thought', Colin Johnston argues that Wittgenstein's objection to Russell's multiple relation theory of judgement, which concerns the theory's failure to preclude nonsense judgements, was intended to demonstrate that the theory, even in its final version, fails to account for synthesis in thought: a judgement's representation of the entities it concerns as combined. On the multiple relation theory, a judgement is a complex in which the judgment relation relates (at least) the judging subject and the judgement's 'objects' - the constituents of the complex that must exist if the judgment is to be true. The relating relation of the latter complex occurs in the judgment complex as term, so can by a general substitution principle to which Russell was committed, Johnston argues - be replaced by a particular to yield a logically possible complex. However, this new complex is a nonsense judgment: its relating relation is judgement, but its objects are not of the right types to combine into a complex; it cannot, therefore, represent them as combined. But the theory fails to explain how the original judgment differs from the nonsense judgement such that the former represents its objects as combined while the latter does not. 
I cannot help thinking that if Johnston's account of Wittgenstein's criticism is right, there is a blunt response available to Russell: the difference is precisely that the objects of the original judgement are logically combinable, while those of the nonsense judgement are not; that explains the difference in representational success between the two complexes. It therefore strikes me as unlikely that Wittgenstein's nonsense judgment criticism is linked to a concern with synthesis in thought in the way Johnston proposes. The presentation of the criticism in the Tractatus (5.542) strongly suggests, moreover, that for Wittgenstein it is the mere possibility of nonsense judgment on Russell's theory that proves the theory mistaken, not further problems about explaining representation in light of this possibility. Nevertheless, Johnston presents a valuable and commendably clear exposition of the dynamics of Russell's theories of complexes and judgment.

Peter Hanks' paper is a study of the development of Wittgenstein's account of judgement from the 'Notes on Logic' to the Tractatus. In the Notes on Logic, Hanks argues, a judgement proposition, 'A judges that $p$ ', is analysed as saying that $A$ is in one of two categories defined relative to the true-false poles of $p$. By contrast, according to the Tractatus, Hanks claims, the judgement proposition serves to display two propositions in tandem $-p$ and a proposition depicting $p$ - and thereby show the correspondence between their constituents. Both of these accounts, Hanks contends, are products of Wittgenstein's grappling with the same dilemma concerning judgment propositions: that the subordinate proposition, 'p', cannot occur as argument to a predicate or truth function, and yet must occur as a complete proposition.

The paper is instructive and engaging. Here I shall just raise two objections. The first concerns Hanks' diagnosis of Wittgenstein's dissatisfaction with the 'Notes on Logic' account of judgement. One source of dissatisfaction, he claims, was Wittgenstein's wider dissatisfaction with the theory of sense on which the account was based. According to that theory, predicates are correlated, in name-like fashion, with relations; and this, Hanks says, 'is in obvious tension with the idea [which Hanks attributes to the Tractatus] that a predicate is a relation that holds names together in sentences' (p. 52). Actually, the alleged tension here is not 'obvious' at all. It is not 
obvious why a relation among names cannot itself be the name of a relation. Indeed, I think that is exactly what Wittgenstein holds in the Tractatus and I'm not alone (see e.g. Hintikka and Hintikka (1986: 37-9) . Secondly, Hanks notes that according to Tractatus 5.542, 'A judges that $a \mathrm{R} b$ ' is of the form " $a \mathrm{R} b$ " says that $a \mathrm{R} b$ ', and rightly claims that " " $a \mathrm{R} b$ "' is not, for Wittgenstein, a name of the sentence ' $a \mathrm{R} b$ ', but rather 'a fact in which names for names are arranged so that they depict the sentence ' $a$ R $b$ " (p.58). We are then asked to suppose that a mental sentence with the sense of ' $a \mathrm{R} b$ ' occurs in A. He reasons thus: "The quoted sentence " " $a \mathrm{R} b$ "' ' is a picture of this mental sentence, since A's mental sentence has the same sense as ' $a \mathrm{R} b$ ' and " $a \mathrm{R} b$ " ' is a picture of ' $a \mathrm{R} b$ ' " (p.58). However, this is fallacious. From the fact that a $\mathrm{X}$ is a picture of $\mathrm{Y}$, and $\mathrm{Y}$ is itself a picture with the same sense as a picture $\mathrm{Z}$, it does not follow that $\mathrm{X}$ is a picture of $\mathrm{Z}$. $\mathrm{Y}$ and $\mathrm{Z}$ may, after all, be different facts.

Steward Candlish and Nic Damnjanovic's essay, 'The Tractatus and the Unity of the Proposition' is, in my judgement, both one of the most interesting essays in the collection and the essay most in error. Their topic is the young Wittgenstein's treatment of the several problems the authors rightly distinguish under the rubric, 'the unity of the proposition'. Setting the context with a survey of Frege and Russell's views, they contend that Wittgenstein's theory of the proposition in the Tractatus dissolves many of the problems - in particular, the problem of explaining "how it is that propositions represent the world" (p. 83) ("Representation") and the problem of explaining what it is that distinguishes a proposition from a mere collection of its constituents (“Unity”). Wittgenstein's position dissolves Representation because, they claim, he denies that propositions by themselves represent the world; rather, representation is accomplished only by our using propositions as pictures. The authors' sole evidence for the claim according to Wittgenstein propositions do not themselves represent is Tractatus 3.13, in which Wittgenstein says that "A proposition, therefore, does not actually contain its sense..." They reason: "Since propositions do not contain their senses, they are not essentially significant." (p. 82). But this simply does not follow. That the sense of the proposition (the situation it 
represents) does not enter into the constitution of the proposition does not entail that the proposition only accidentally represents its sense. And it is plain, on the contrary, that Wittgenstein did hold that propositions essentially represent their senses. The authors completely ignore the fact that he says so: 'A proposition communicates a situation to us, and so it must be essentially connected with the situation./ And the connection is precisely that it is its logical picture." (4.03, original emphasis). Wittgenstein's position dissolves Unity, the authors claim, because according to Wittgenstein 'Propositions are not really unities, at least not in the sense that facts, objects or people presumably are, since they are propositional signs in their projective relation to reality" (p. 83). I find this argument baffling. Given that propositional signs are facts (3.14) and thus unities on the authors' conception, how does a proposition's being a propositional sign in its projective relation to reality support the conclusion that it is not a unity? The authors insist, in particular, that Tractarian propositions are not facts, though the only textual evidence they adduce is that Wittgenstein only explicitly says in the $3.14 \mathrm{~s}$ that propositional signs are facts. Again, given that Wittgenstein has just (3.12) told us that propositions are propositional signs in their projective relation to reality, this is hardly compelling evidence. Moreover, the 3.14 s, on the contrary, do make plain that Wittgenstein holds propositions to be facts, for he says "Only facts can express a sense", and in numerous locations says or implies that propositions express their senses (e.g. 3.34, 3.341, 4.4 in light of 4.2, 4.431)

The remainder of the essay is, in my view, likewise marred by multiple errors and imprecisions in the representation of Wittgenstein's views. I say, nevertheless, that this paper is one of the most interesting in the collection because I think the authors have quite correctly identified the problems of the unity of the proposition as a key to the early analytic tradition. However, if I might echo a remark of theirs in their (more insightful) discussion of Frege's views (p. 73), it is one thing to a have a key, another to succeed in opening the door.

In 'Simple Objects: complex Questions', Hans Sluga investigates the roots of Wittgenstein's doctrine that there are simple objects to which unanalysable names refer. He 
argues that the doctrine issues from a number of considerations raised in the 1914-16 notebooks, concerning the divisibility of the visual field and of physical objects, and the analysability of sentences. Sluga argues that these considerations fail to substantiate Wittgenstein's doctrine, and submits that Wittgenstein is here guilty of having recourse to self-evidence, despite having emphatically disavowed self-evidence as a source of philosophical justification. Sluga is probably right in these conclusions. My only serious complaint is that he apparently also wishes to conclude that the insufficiency of justification for the doctrine in the notebooks spreads to the Tractatus. Clearly, establishing that conclusion would involve careful assessment of the argument for substance given in 2.0211-2.0212, which Sluga altogether neglects.

That neglect is made conspicuous by the lucid and original study of the argument for substance contained in the next chapter, José Zalabardo's 'Reference, Simplicity, and Necessary Existence in the Tractatus'. Zalabardo contends that the argument for substance should not be understood as appealing to the problems that allegedly follow from supposing that the referents of names only exist contingently; he argues that no such argument is to be found in the Tractatus. According to his alternative reading of 2.0211-2.0212, the supposition that the world has substance, comprising simple objects, is being presented as requisite if we are to accommodate the possibility of false representation without invoking Russellian logical forms. Zalabardo's essay is very profitably read in conjunction with Michael Morris's excellent discussion of the substance argument (2008: p. 39-50, Appendix), in which Morris criticizes an earlier version of Zalabardo's interpretation. The present chapter includes responses to several of Morris's objections. I will only say here that at least one of Morris's objections seemed to me to be sustained: it seems implausible to suppose, as Zalabardo must, that Wittgenstein assumed that the only possible alternative to his own view was Russell's.

Chapter 6 is a characteristically rich essay from Cora Diamond. The paper is hardly streamlined - more than one paragraph spans five pages - but does present a deep and challenging discussion of issues crucial to our understanding of the Tractatus. Wittgenstein claims, 
in 4.1272, that legitimate uses of formal concept words like 'object' and 'function' are rendered in a correct logical notation as variables. Diamond is concerned to establish, pace Peter Sullivan in his (2004), that Wittgenstein likewise recognises legitimate uses of the formal concept word 'proposition' that translate into variables in a correct notation, and that the variable Wittgenstein identifies as the general propositional form, $[\bar{p}, \bar{\xi}, N(\bar{\xi})]$, can play this role. Diamond's defence of these claims appeals to a permissive reading of Wittgenstein's thesis that 'In the general propositional form propositions occur in other propositions only as bases of truth operations' (5.54). According to Diamond, this claim must be intended as consistent with the possibility of a proposition in which another proposition occurs as the base of a non-truthfunctional operation, because the possibility of such a proposition follows from remarks in the 5.2s concerning operations and internal relations. What 5.54 requires, she holds, is that any such proposition also admit of formulation in such a way that the only propositions occurring in it occur as bases of truth-functional operations. Imputing this 'weaker form of extensionalism' (p. 183) to the Tractatus allows Diamond to find a role for the variable, $[\bar{p}, \bar{\xi}, N(\bar{\xi})]$, in the correct formalisation of innocent uses of 'proposition', and furthermore, she thinks, allows us to make sense of Wittgenstein's puzzling treatment of 'A believes that $p$ ', 'A says that $p$ ', etc., in 5.542

I found the paper to be an impressive response to Sullivan's argument that no 'worthwhile use' can be found for $[\bar{p}, \bar{\xi}, N(\bar{\xi})]$, and I am broadly in sympathy with Diamond's liberal reading of 5.54. I have reservations, however, about her discussion of Wittgenstein's claim (5.542) that 'A says that $p$ ' is of the form " " $p$ " says that $p$ '. Firstly, her interpretation of this claim (p. 178) strikes me as seriously strained, given what Wittgenstein actually says. Secondly, though Diamond notes that Wittgenstein held that propositions, qua facts, are unnameable, her discussion fails, I think, to take full measure of the expressive difficulties this commitment engenders. Like Hanks, she proposes that Wittgenstein can make 
use of the convention of enclosing a propositional sign in quotation marks, providing the result is conceived as 'an abbreviation of a description of the propositional sign-fact' (p. 167) - i.e. not as a name, but a new proposition that asserts the obtaining of the fact with which the first is identified. But she proceeds persistently to flout that conception by using quoted propositions in contexts that demand that they be names and not themselves propositions. For example, she proposes that a translation rule can be formulated as follows: "Guillaume défit Harold"sf is a translation of "William defeated Harold"sf (p. 170) (the 'sf' superscript is meant to signal that quotation is being used in the way proposed). But if the expressions flanking is a translation of are really propositions, this isn't even well-formed. Elsewhere she avoids ill-formedness by just resorting, unannounced, to naming facts - e.g. "the fact that "William" stands to the left and "Harold" to the right of "defeated" (p. 169). Perhaps Diamond is expecting a pinch of salt; in which case, she ought at least to ask for one, rather than ignoring the very serious difficulties here, which are graver relatives of Frege's concept horse problems.

In his paper, 'Russell's Merit', Michael Kremer focusses on Wittgenstein's remark, in 4.0031, that 'Russell's merit is to have shown that the apparent logical form of a proposition need not be its real form.' Kremer argues that the 'obvious' reading of this remark, according to which Wittgenstein is referring to Russell's theory of descriptions, is unsatisfactory in at least three respects: firstly it fails to explain why this merit is attributed to Russell in particular, when Frege seems equally to deserve to be credited with demonstrating that apparent logical form can belie real logical form; secondly, it fails to connect 4.0031 with the discussion of the nonsensicality of philosophical propositions in the passage on which it comments, 4.003; and thirdly, it fails to show how Russell's merit is a contribution to the conception of philosophy as a critique of language - a conception affirmed in 4.0031. Kremer proffers an alternative reading of Wittgenstein's remark, on which Russell's distinctive merit is to have shown, particularly in his treatment of logical puzzles in 'On Denoting', that there are forms of nonsense-generating 
equivocation that issue from structural ambiguities in a sentence and that can only be exposed by application of 'something like a Begriffsschrift'.

The paper is a cogent and instructive treatment of a vital tract of the Tractatus, 4.002-4.0031. Whether or not the alternative reading advanced in the paper proves tenable, Kremer's merit is to have mounted a thoughtful challenge to the standard reading. There is, however, one conclusion Kremer draws in the course of defending his reading with which I must disagree. At 3.323 Wittgenstein speaks of 'identical' figuring as an adjective, but at 5.4733 tells us that 'we have given no meaning to the word "identical" as adjective' (this, and only this, is why 'Socrates is identical' is nonsense). Kremer concludes (pp. 218-19) that the adjectival use of 'identical' to which Wittgenstein refers in 3.323 must be a nonsensical philosophical usage - a usage on which 'identical' is intended as synonymous with 'self-identical', as expressing a property absolutely everything possesses. But Kremer's conclusion is starkly at odds with the fact that 3.323 is clearly concerned with perfectly ordinary uses of expressions: indeed the section begins, 'In everyday language [Umgangssprache].... Wittgenstein is concerned in this passage to highlight two features of everyday language: firstly, that one word can signify in different ways; and secondly, that two words can signify in different ways though they superficially feature in propositions in the same way. All the other examples adduced in this passage are, and need to be, cases of entirely quotidian uses: 'is' occurring variously as copula, identity sign, and quantifier (illustrating the first feature of everyday language); 'exist' occurring as an intransitive verb like 'go', (illustrating the second), etc.. It is far-fetched to suppose, as Kremer does, that Wittgenstein has thrown into this passage an example of a specialised metaphysical use of an expression. Such an example would be inexplicably out of keeping with all the other cases mentioned, and wouldn't illustrate the points Wittgenstein is here concerned to make. Rather, I submit, Wittgenstein must be referring in 3.323 to the use of 'identical' as it occurs, e.g. in 'Charles Dodgson and Lewis Carroll are identical'. Here, 'identical' features in what is superficially the same way as, say, 'male', in 'Obama and Cameron are male'. But the superficial similarity belies a difference in these words' 
respective modes of signification, illustrating the second feature of everyday language Wittgenstein is concerned to indicate in 3.323 . This is to be reconciled with 5.4733 , I propose, as follows: in 5.4733 Wittgenstein is referring specifically to the occurrence of 'identical' as an adjective copulated with a single subject by a singular form of 'to be', as in the example under discussion: 'Socrates is identical'. No meaning, Wittgenstein is claiming, has been given to 'identical' figuring as adjective in this way. He does not, in 5.4733, mean to deny that meaning has been given to 'identical' as it as it occurs as an adjective copulated with multiple subjects by a plural form of 'to be', as in 'C.D. and L.C. are identical'. This reconciliation of 3.323 and 5.4733 involves supposing Wittgenstein to have been a little sloppy in these passages, but that's not hard to believe.

Marie McGinn's stimulating contribution examines what Wittgenstein describes in the Investigations as our 'tendency to sublime the logic of our language' - a tendency to which Wittgenstein evidently takes himself to have succumbed in the Tractatus. She argues that this tendency is not just a matter of our propensity to overgeneralize about language, but also of our disposition to conceive of naming, meaning and understanding as queer or remarkable acts of mind. In his later work, Wittgenstein's methods for countering the sublimating tendency amount, McGinn argues, to a distinctive form of naturalism.

Brian McGuinness's paper is ostensibly addressed to the exegetical campaign of the selfstyled 'New Wittgensteinians', but readers conversant with the controversies attending the 'new' programme of interpretation shouldn't expect major contributions to the debate. Apart from an undeveloped objection to the effect that the New Wittgensteinian slogan 'Nonsense is just nonsense' is itself nonsense, McGuinness's only charge against the 'new' school of interpretation concerns precisely its novelty. He clearly thinks that many of its putative discoveries are at best rediscoveries, and admonishes its proponents for having neglected earlier readings (including McGuiness's own) that similarly depart from what he wittily dubs the 'Oxfordoxy'. This charge occasions reflections on why the New Wittgensteinians were looking for something new in the 
first place. McGuinness's answer is that Wittgenstein's peculiar style and personality foster a sense, in each generation of readers, that his work needs to be engaged with anew. The value of the paper lies in its admirably learned and relaxed discussion of Wittgenstein's character and literary style and their bearing upon the interpretation of his philosophical work. I confess I'm hesitant to give biographical and stylistic considerations quite the centrality in interpretation that McGuinness wishes to, but there is much in the paper that is illuminating. McGuinness shows, for example, that there is reason to believe that Wittgenstein harboured a deep and long-standing moral esteem for the impulse to produce certain kinds of philosophical nonsense. It is an interesting question, I think, how this consideration is to shape our conception of Wittgenstein's purposes in the Tractatus, and in particular, our understanding of text's closing injunction (if such it is) to remain silent.

This is a valuable book that I am happy to commend to all students of early analytic philosophy. While some of the essays in the collection contain, in my judgement, serious errors, all are of interest, most are insightful and some represent considerable progress on the issues they address.

Michael Price

\author{
Faculty of Philosophy \\ University of $\mathrm{O}$ ford \\ michael.price@philosophy.ox.ac.uk
}

\title{
REFERENCES
}

Hintikka, M. B. \& Hintikka, J. (1986) Investigating Wittgenstein. Oxford: Basil Blackwell

Morris, M. (2008) Routledge Philosopby Guidebook to Wittgenstein and the Tractatus. Oxford: Routledge

Sullivan, Peter M. (2004). 'The general propositional form is a variable' (Tractatus 4.53). Mind 113 (449):43-56. 